\title{
THE RATE-MAKING PROCESS IN PROPERTY AND CASUALTY INSURANCE-GOALS, TECHNICS, AND LIMITS
}

\begin{abstract}
C. A. KuLP*
The general title of this symposium is Regulation of Insurance, but it is no accident that most of the papers deal with one aspect or another of insurance rates and their regulation. So central indeed is the rate to the concept of insurance or riskpooling that an adequate treatment of insurance regulation cannot avoid it. It is the special purpose of this paper to present an analysis of the objectives of the actuary or rate-maker; of the technics he devises; and of the handicaps, technical, social and other, he must surmount or ignore to achieve these objectives. We seem constantly to forget it, but it is no more fair to judge the rate-maker's product without reference to his goals than that of any other craftsman or professional, and unless his limits as well as his objectives are kept plainly in the foreground he will often be criticized for failing to do the impossible, or even the unnecessary and undesirable. It is not possible nor desirable to carry this emphasis on technical, vis-à-vis legal principles beyond a certain point, but as far as is practicable the approach in this paper will be in terms of the former. Insurance is a technic or a principle before it is a business, and it is a business before it is a legal institution. The present paper will center on the principles on which both business and institution rest and without which neither would be possible.
\end{abstract}

\section{I}

Nature and Function of the Insurance Rate

The premium or rate is the price charged for insurance. (There are technical differences between them, but for the present purpose the two will be used interchangeably.) The rate has essentially only two functions. It should produce total funds sufficient to cover the insurer's obligation; it should distribute the cost of insurance fairly among insured persons. We expect today that a rate will meet both tests, but the first is clearly the more important. The essential requirement of insurance is that it be sure; actuarially this means that on the average the rate must be sufficient to meet losses and insurer expenses of administration. Historically this is also by far the older function, and naturally so, because a scheme designed to pool risks and increase the margin of certainty in human affairs that cannot be counted on to pay off at roo per cent is hardly better than no insurance at all. The first obligation of the insurer is to keep solvent.

But there are reasons for this primacy of rate adequacy even more intimately con-

- B.S. 1917, Wharton School, University of Pennsylvania; A.M. 1921, Ph.D. 1924, University of Pennsylvania. Professor of Insurance, University of Pennsylvania. Contributor to professional journals. 
nected with the business, as distinct from the science of insurance. A rate that errs on the redundant side is naturally the first objective of the insurance pioneer, when costs still are unknown and when insurance would hardly be available at all were it not for the willingness of the enterpriser himself to take considerable risk. Generally speaking, the newer the insurance and the fewer the number of individual risks insured, the greater the emphasis on rate adequacy. The special case of the life insurance rate is discussed below.

The second major requirement of a sound rate-that it share insurance costs fairly among those insured-has been a much later technical development. Rates designed to be fair as well as adequate had to wait for the development of credible experience and indeed of the science or art of the actuary itself; making a fair rate is technically a far more complicated process than making one that is simply adequate. Competition, it is sometimes said, may work in the direction of fair rates, but the force of competition, to say the least, is slow and its direction uncertain, and it has as often as not produced rates neither fair nor adequate.

Sometimes rates are required to meet additional tests, but on examination these are discovered either to be sub-tests to those we have been discussing or to be of very minor importance. A rate or rate structure, for example, should be, it is said, reasonably responsive; that is, it should not be so out of date that it represents risk conditions no longer in effect. Since (see below) all rates with one exception are prospective in character-rates based on the past are applied in the future-the ratemaker must always be alert to the possibility that his rate under today's conditions is too high or too low. But this is only another way of saying that the rate no longer represents a fair allocation of cost among insured risks and is therefore inequitable. A sound rate or rate structure should also be stable. For technical, apart from all other, reasons, a rate that jumps erratically from period to period (particularly, as in casualty insurance, where the typical period of coverage is one year and rates are revised annually) is unsound and undesirable. An unstable rate is evidence either that the basic rate data lack credibility or actuarial reliability or that the rate-maker is incompetent or both. In either event the adequacy of the rate is also in jeopardy.

Finally, a rate may be expected to encourage the reduction of loss. Sound insurance principle requires, however, that this objective be kept clearly secondary to those of equity and adequacy. Insurance after all is a device to pool risk and share losses. To the extent that the insurer can soundly and fairly combine provision of safety incentives with this fundamental purpose of insurance, very good. But the condition definitely limits the role of the rate as a safety incentive. When safety is made the main end of the rate structure, this end, as in workmen's compensation schedule rating, may indeed be achieved but at the price of so great a failure in rate equity that (with rare exceptions) it has had to be abandoned. On the other hand, if the safety objective is kept subordinate to these other objectives, the effectiveness of the safety incentive is greatly restricted. This is because the amounts of reward 
and penalty that can fairly and safely be offered the insured will not be large enough to influence his attitude toward his risk.

The statutory standards for acceptable insurance rates broadly parallel the technical requirements we have been discussing. Quite commonly the statutory statement of the first standard is that the rate must be adequate but that it must not be unreasonable, that is, unreasonably high for the risks to which it applies. There is an upper as well as a lower limit to adequacy. The equity standard is commonly expressed in language such as the following: ${ }^{1}$

No rate shall discriminate unfairly between risks involving essentially the same hazards and expense elements or between risks in the application of like charges and credits.

The first statute in this country to regulate insurance rates, the Kansas fire rate law of Igog, included both anti-discrimination and adequacy-reasonableness standards. $^{2}$ The great majority of early rate laws, including the New York law of Igrr, however, included anti-discrimination standards only. ${ }^{3}$ In passing it is interesting to note that insurers perceived the advantages of adequate fire rates much earlier than did the state legislatures. The latter indeed had been attempting for years through anti-compact laws applied to insurance, to assure that rates, as a result of insurer combination and monopoly, would not be too high.

This discussion of rate standards would not be complete without a word on the reasons for restricting the subject of this paper to insurances other than life. The fact is that the making of life insurance rates, as distinct from other features of the life insurance business, is not regulated directly at all, and when it is regulated indirectly, as through reserve standards, the rates are regulated with reference to their adequacy only. It has sometimes been surmised that one reason for this exemption is the superiority of life insurance loss and exposure data as measures of insurance cost. But this explains why life insurance rates can be made with relative confidence of their adequacy rather than why it has not been necessary for the state to assure that they are so made. The history of assessment life insurance suggests that there must be other and stronger reasons for the exemption of the life actuary from rate regulation. More to the point is the preference of technician, insured person, and legislature for a rate exceedingly simple, even crude; one that ignores for the great mass of insured persons all criteria of risk except that of age. All things equal, the cruder the rate structure the sounder, and for a risk as long in term as that of life and with so much of weal and woe hanging on the expectation that the contract will some day be honored in full, a precisely equitable rate is far less important than an adequate rate. This same preference for adequacy is illustrated in the immense popularity of the participating life contract, the rate for which includes a loading intended to provide a margin for policyholder dividends but which in the meantime raises the rate well above that of non-participating contracts. It is hardly a qualifica-

${ }^{2}$ N. Y. INS. LAW $\$ 183(c)$.

2 Clarence W. Hobbs, XXVIII Proceedings Casualty Actuarial Society 346-348 (r942).

' Louis H. Pink, The Probleas of Rates 4 (1942). 
tion on this point either to note that the redundancies and crudities of the life participating premium may later be corrected through dividend schedules that may attempt a more precise allocation of cost among insured classes. These dividend schedules are not subject to state regulation except as to their application, and while they give the opportunity for further rate refinement, neither law nor public demand assure that they do so. State regulation of life insurance reserves, it should be noted, is an important indirect control on the adequacy of the life rate structure, and all the more because the rationale of life reserve statutes is that the insurer at all times must estimate, and protect, his outstanding liabilities prospectively. But life reserves, however carefully established, provide guarantees of adequacy only, none of equity.

II

\section{Kinds of Insurance Rates}

Insurance rates may be classified from several points of view. One of the most fundamental is on the basis of what may be called the insured unit, that is, broadly stated, whether the rate is computed as a broad average for all risks that have approximately the same loss-producing characteristics or separately for the individual risk. (By individual risk the actuary means the combined exposures of a single insured.) Stated more precisely, since insurance rates even for the individual risk must be made by application of the law of averages, the distinction is one based on the extent to which the rate paid by the individual insured is affected by experience other than his own. It is a little difficult to find names for either of these rates. It may come as a surprise to the non-specialist, accustomed to regarding insurance as one of the exact sciences, but the terminology of insurance is the very reverse of standard, descriptive, and orderly. The same technical term, schedule rate, for example, is used in different insurances with quite different meanings; other terms, group, for example, have both a variety of technical meanings as well as a general one. In the analysis that follows careful distinction needs to be made, therefore, between the concepts that underlie rate-making technics and the various names that may be given to their local and special application.

Rates for the very great majority of risks in all lines are made, and in the nature of the case must be made, not for the individual risk but as averages for the members of a group of risks with essentially the same loss-producing characteristics. Manual rates in workmen's compensation and automobile insurance; fire insurance class and blanket rates; rates on the individual in life and disability insurance, are examples. Likewise, schedule rates in fire insurance, which result from the application to large and complex individual risks, of schedules of debits and credits reflecting the good and bad features of the risk. The rate here is applied, it is true, by examination of the individual risk, but it is clear that the function of the schedule-to identify, classify, and rate identically all individual risks having similar construction, ex- 
posure, and occupancy characteristics-is to produce a rate based not on the actuarial characteristics of the individual risk but on what might be called its family characteristics. Other examples of this kind of rate, despite surface dissimilarities, are the much simpler schedules used in burglary and glass insurance. Even though the term group has been applied in life and disability insurance in rating the individual risk, the kind of rate we have been discussing is most accurately described as a group rate.

The essential reason that most risks must be rated on the basis of broad group averages is that alone each risk is so small that its individual experience lacks the credibility or actuarial reliability essential to a sound rate structure, hence the combination in classes of risks with broadly the same loss-producing characteristics. To the extent that the individual risk is large enough to develop credible experience of its own, both good business practice and equity require that the risk be freed from multi-risk averages and put on its own. The criterion of risk size is the number of exposure units: number of workers or dollars of payroll in workmen's compensation; number of workers in group accident and health; number of automobiles in automobile fleet, and so on. As exposure units increase in number for the individual risk, the rate-maker finds theoretically and empirically that he can put more and more weight on its experience, less and less on the family averages. In this kind of rate-making the actuary does not of course ignore averages; what he does, as individual risk credibility rises and falls, is shift the relative weights of the group experience and of the individual risk. In workmen's compensation prospective experience rating for example, even of those relatively few risks that meet the minimum requirements of eligibility, the great majority are not completely eligible. To the extent that the individual risk cannot establish roo per cent credibility for its experience, to that extent does the rate-maker have to combine with individual experience the experience of the group to which it belongs. Even if the risk qualifies for self-rating-is so large that group experience is ignored entirely-the system remains one of averages. This essential tie between group and individual risk experience is shown also by the fact that in workmen's compensation prospective experience rating the individual risk rate is computed as a debit or credit on the manual or group rate, never as an independent calculation. Another evidence of this use of the group averages as controls is that no prospective rating plan is considered sound that does not produce as many dollars of premium over the average as below: the reduction in total premium for better-than-average risks must equal, but no more than equal, the increase in total premium for poorer-than-average. Retrospective experience rates, it is true, are calculated with no direct reference to the manual or group rate, but this exception is apparent rather than real since the result of the rate-making process here is essentially a variety of self-rating, and is sound only to the extent that the individual risk establishes its own experience credibility. ${ }^{4}$

Examples of individual risk rates are prospective experience rating in workmen's

"For an explanation in greater detail, see C. A. Kurp, Casualtr Insurance 574-576 (rev. ed. 1942). 
compensation, automobile, and liability insurance; schedule rating in workmen's compensation insurance; ${ }^{5}$ and in part retrospective experience rating now applied in workmen's compensation, automobile, and general liability insurance. Individual risk rate plans have had wide development in casualty insurance, where in recognition of their equity objective, they are often referred to as merit rates. They have not been applied, except very crudely and partially, in fire insurance at all.

To trace all the reasons that account for this difference between fire and casualty insurance would require space out of proportion to the importance of the subject in this paper. A few general indications will suffice. The most important reason, perhaps, is the superiority of the actuarial materials available to the casualty, and particularly workmen's compensation and liability, rate-maker, which at one and the same time reveal to him, and to the insured, the inequities of the manual rate in the individual case and a way to correct them. The compensation-liability rate-maker, for example, unlike the fire, has relatively objective units of exposure, no problem of under-insurance. Casualty lines also represent for the average insured a much higher proportion of personal or business expenses; casualty costs show much wider variation than fire from year to year and between the best and the poorest members of a classification (for example, large and small compensation risks); and individual casualty risks are much more often large enough to give individual risk experience a high degree of credibility and to suggest, in combination with the other characteristics we have listed, the possibility and the desirability of self-insurance, always a potent influence on the attitude of the rate-maker. The casualty insured takes a close interest in his rates; the actuary must also. Finally, the art or science of casualty rate-making, like casualty insurance itself, is a recent development. From the beginning the casualty actuary has worked in a business and social atmosphere in which it was taken for granted that he would use the most precise actuarial tools available, that the insured (and the beneficiary) has a stake in the rate-making method at least as vital as that of the insurer, and that the equity of a rate is at least as important as its adequacy. In this connection it is revealing to note that despite hundreds of years of fire insurer precedence, the profession of fire actuary is still to appear. The casualty actuary dates from the opening of the second decade of this century.

\section{III}

\section{Rate-Making Technics}

\section{A. Loss Ratio}

What I have been discussing up to this point are the kinds of rate that result as the end-product of the rate-making process. More important for the present purpose is consideration of the method, technic, or philosophy the rate-maker applies in

' Workmen's compensation schedule rating is properly classified as individual risk rather than group. While debits and credits are assigned after an engineering inspection of the loss-producing characteristics of the individual risk, the process is applied only to those few members of the classification eligible, and the resulting net debit or credit is applied to the average or manual rate for the classification. 
producing this end-product. Again there are essentially only two approaches: the rate may be the result of applying the loss ratio method, the pure premium method, or a combination of the two. As the discussion that follows will show, what sometimes is referred to as a third approach-that of judgment-is more accurately described as a subfactor entering necessarily and in various degree into the two basic technics.

The older of the rate-making technics is the loss ratio: the new rate or average rate level for multi-groups is determined by comparison of actual with expected or permitted loss costs and an adjustment upward or downward of the old rate to bring the new rate in line with the most recent experience. This is the method traditional in property insurance including fire, marine, burglary, glass, and power plant; it continues, without the justification in property insurance lines, as the principal technic in commercial accident and health insurance. It will be illustrated by a simplified analysis of the method of making glass rates used by the National Bureau of Casualty Underwriters.

The glass rate (like any other) is made of two main elements: that part intended to cover losses, or pure premium; that part intended to cover expenses. At the time of the last pre-World War II examination of this rate structure by the New York Insurance Department ${ }^{\mathfrak{b}}$ the per cent of total premium set aside for losses, or the expected loss ratio, was .423; the ratio for administrative expense and profit was .577 . For the calendar years $1934-1938$ the actual loss ratio-the proportion of premiums written for the 5-year period used to pay losses as distinct from administrative expenses-for the state of New York was .362 . That is, other things equal, the general rate level charged under the rates in force would appear to be too high to pay losses expected by the difference between .423 and .362 or by approximately 15 per cent. All other things equal, therefore, a reduction of $x_{5}$ per cent in the state-wide glass insurance rate level is indicated. But as this revision illustrates, other things are usually not equal, and a $\mathrm{I}_{5}$ per cent reduction is justified only if the probabilities are strong that the experience of the 5-year period past will be exactly reproduced in the period for which the new rate is calculated. If, for example, there have been rate reductions downward during the experience period, actual loss ratio figures unless adjusted will understate the true loss level because the same number of insured units of glass exposure will produce a lower total of premiums than is shown in the historical data, though, other things equal, they will produce the same number of dollars of glass loss. Because there was such a reduction, the actual loss ratio in this revision was adjusted to .395 , which produced an indicated rate level reduction of 7 per cent. The role of the judgment factor in making rates by the loss ratio technic is illustrated by the fact that no attempt was made in this revision to take into

\footnotetext{
- At that time, the name of the organization was National Bureau of Casualty and Surety Underwriters. A pre-war example has been selected because the report of the only examination since that time, of July I, I947, covers principally the war years when normal actuarial procedures and controls, particularly for smaller premium volume lines, had to be sharply curtailed.
} 
account the effect on losses of policy liberalizations effective with this same revision, or of other minor changes which might be expected to raise the actual loss ratio. The reduction in the state-wide rate level approved by the New York Insurance Department was approximately 6 per cent. ${ }^{7}$

The influence of the judgment factor on this kind of rate-making is shown also in the action of the New York Department in the 1947 fire insurance revision, which against a permitted loss ratio of 475 approved a general rate increase of 8 per cent instead of the indicated 4 per cent increase because of an upward trend in building costs. Another example is the policy of the New York Department not to approve rate revisions unless the indicated change is more than $2 \frac{1}{2}$ per cent up or down nor to approve revisions of more than 25 per cent. ${ }^{8}$

This brief exhibit suggests the advantages and limitations, the strengths and weaknesses, the inherent as well as some of the acquired characteristics of the loss ratio technic. It is first and foremost an exceedingly simple approach, as simple as the simplest arithmetic. It is in fact not a method of making rates at all but a way of revising rates from time to time with an eye principally to assurance of an adequate over-all rate level. The essence of a fair rate structure however is an equitable system of classified risks; in this respect the loss ratio technic is very defective because it provides only a most indirect and uncertain guide for deciding whether a given individual risk belongs in this classification family or that.

The test of risk homogeneity is whether over an appropriate period the members of a family of risks are likely to develop-reasonably-like loss experience. One way of deciding this is to look at the risks-the fire rate-maker calls this inspectionand by the application of a mixture of experience, acumen, and instinct called underwriting judgment, estimate their loss potentialities. This way is used most widely, and most justifiably, in marine insurance where objective materials for making rates are least available and where every risk more or less is unlike every other. Another way is to compute for each risk or each group of risks a pure premium expressed as so many dollars of loss cost per unit of exposure, for example, per hundred dollars of workmen's compensation payroll, per automobile, per thousand dollars of burglary protection. The advantage of the pure premium approach is twofold: underwriting results are expressed directly in terms of units of exposure and not, as in the loss ratio, of dollars of premium; there are no limits except those of practicability to the degree of refinement with which loss and exposure data can be manipulated, and thus to the extent to which the actuary may push his search for homogeneity. At each revision he calculates a brand-new rate from the ground up; with the loss ratio technic he adjusts an old rate which itself is assumed to have been equitable. Under the pure premium technic the actuary can make any number of combinations he wishes of his data; he can, and does, combine, divide, and revise

\footnotetext{
${ }^{7}$ Insorance Departicent, State of New York, II Report on Examination of National Bureau of CASUALTy and SuRETy UNDERWRITERS 209-2II (I94I).

'Walter F. Martinead, The Revision of Fire Insurance Rates 15, 20, 25 (address given before Rating Personnel at Richmond, Va., September, I947).
} 
his classifications as experience indicates. He will of course end up with rates for risk classifications, but in the meantime he is much less apt to be averaging the dissimilar. Since the most reliable test of homogeneity is similarity of loss experience, this approach to rate-making, even though the majority of individual risks develop no credible experience of their own, is the most nearly ideal. It does not, as we shall see, suit all kinds of insurance, but where it can be applied there is no question of its technical superiority. Unlike the loss ratio method it gives the rate-maker a relatively precise tool that he can use to achieve a rate not only adequate in general level but equitable among risks and risk groups.

The loss ratio technic operates on the assumption that risk homogeneity is established when on the average the combined risks in each classification require the same proportion of total premiums to pay losses. Now while it is obvious that this may show equity of insurance cost allocation between classifications, the technic offers the rate-maker slight opportunity to determine whether the individual members have been put in the proper classification in the first place. Modern standards of rate equity require equity among classification members as well as between members of different classifications. He could, were he so minded, push his analysis of experience further and further back until he reaches the individual risk, and in principle the further the rate-maker pushes his analysis of loss ratio figures the nearer his results could be made to approximate those of the pure premium technic. In fact, the loss ratio rate-maker is not interested in precise actuarial-statistical analysis, and indeed is often openly suspicious of it. The reasons are various. He does not of course admit that he is not as eager for rate equity as the pure premium actuary. His argument is partly that the rate-making problem in his lines makes the pure premium method inapplicable; partly that his rates in the long run are just as equitable, and more often adequate. There is in fact something to be said for this argument. Take first the technical reasons. In general the rate-maker deals with lines in which the exposure unit is very defective, for example, dollars of insurance value in fire and burglary insurance. Sometimes as in glass and burglary insurance he is handicapped by small volumes of exposure, often exaggerated by a multiplicity of loss causes that further dilute the credibility of the experience. Sometimes as in fire, power plant, and some burglary lines, loss frequency is low, which has additional repercussion on the reliability of the averages.

It would be naive indeed to conclude however that the only reasons for the failure to make use of, or at least to experiment with, pure premium rates are technical. The reasons at least as often are traditional. The position of the fire companies on two much milder suggestions for improving the fire rate structure will illustrate. For years the New York Insurance Department has been urging, not the abandonment of the loss ratio approach, but two proposals designed to assure greater equity of fire insurance rates derived by the loss ratio method. One of these is adoption of a more orderly and more precise system of classifying experience and one bearing a closer relationship to the fire rates charged. Following enactment of a new rating 
law in New York, successive Superintendents since 1934 have repeated that "a review of fire insurance rating systems reveals two weaknesses: lack of proper statistical information and rating methods unsupported by statistical experience." The industry has been reluctant to accept either the facts alleged or the recommendations.

The reader may judge for himself to what extent the argument of the opposition is technical or traditional-emotional. The extreme wing of the opposition goes so far as to call fire rates made on classification experience ". . . a major threat to an orderly and equitable rating procedure."10 The argument in part is that since fire "hazard is potential as well as active" (loss figures do not accurately measure fire risk), fire rates made on classified experience would not be equitable. "Classified statistics simply have no vitally important part in rating ... [In fire schedules] individual charges are empirical-arbitrary-but they are uniform and relative and, fairly applied, do establish relative fire hazard." Equity, that is, means equity of rate application, not equity built into the rate structure itself. However incorrect any individual charge or credit, the entire system of charges and credits is equitable because all risks are treated alike for the same characteristics.

.The major role of judgment in this kind of rate-making is evident. But even were it possible to use loss and exposure data on a classified basis, the last author would still avoid it because of his fears of rate inadequacy. "There is no assurance whatever that the experience of next year will even approximate the same pattern [as that of the past]. After all, it is our business to measure the likelihood of future losses -not to pay for last year's business." This amounts to arguing that rates made on classified experience - "a plan to gather yesterday's gardenias"-are rates made by clockwork, without benefit of judgment, of trend analysis, of data adjustment of any kind. It is also even stronger proof that judgment is the principal ingredient in the fire rate structure. Despite really remarkable advances in fire construction and fire fighting in the last 50 years, the shadow of Mrs. O'Leary's cow seems actually to grow longer rather than shorter.

There are however signs of progress. As a result of the collaboration of the New York Department, the National Association of Insurance Commissioners, and the Insurance Executives Association, a revised and improved classification system was finally adopted in 1947 and is now in use. It is much too early to judge its results, but ex-Superintendent Dineen expects from the expanded list of IIS classifications "a more equitable apportionment of rates among all classes. Certainly the increased number of classes should lead to better grouping and prevent the old system of lumping together classes of risks which had little or nothing in common."11 For the first time premiums will be reported on the earned as well as the written basis, and losses incurred as well as paid, an advance toward improvement of rate-making at least as important as that of the new classification plan itself.

\footnotetext{
${ }^{\circ}$ Pink, op. cit. supra note 3 , at 17 .

${ }^{10}$ Eugene F. Gallagher, "Fire Insurance Rating Problems," address, Ohio State University, April 30, 1945.

${ }^{11}$ Robert E. Dineen, Five Steps to Better Fire Insurance Rates, American Management Ass'N INS. Series No. 76, 3 (1948).
} 
The second official recommendation for improving the equity of fire rates is that the rate level for all classes should be required to meet a uniform expected or permitted loss ratio standard. The enormous difference in attitude toward rate-making between fire and casualty insurance is nowhere better illustrated than by the fact that a uniform permitted loss ratio has been standard practice for the latter from its beginning, and that in the former the issue is now being bitterly debated and is not yet settled: ${ }^{12}$

The use of a formula . . . has been consistently opposed by the fire insurance business. The reason most commonly advanced is that the fire insurance business in the past has operated on broad general averages and that high loss ratios on some classes and low loss ratios on others are to be expected.

It is not to be expected of course that every year every classification will in fact produce precisely its expected loss ratio; the reference in the quotation is to a policy of expected loss ratio differentials deliberately set by the companies: ${ }^{13}$

I am referring to those classes which as a result of business policy consistently produce high profit ratios while others produce low profit ratios or even losses.

A by-product of this policy deplored by the Department as another variety of inequity is the practice, when general rate level revisions are made, of applying horizontal increases or decreases without reference to the disparities, often considerable, in loss ratios between classifications. It requires no lengthy analysis to arrive at the conclusion of the Superintendent of New York that "Unless a [uniform permitted loss ratio] formula is used on a class-by-class basis there is no way that we know to obey the requirement of the law that equity shall be done between classes."14

The New York Department reports even that "from time to time we have encountered the anomaly of having rating organizations resist increases which were warranted on the figures and at the same time oppose reductions when they were required." "15

Actual fire loss ratios for Pennsylvania for 1942-1946 illustrate the inequities that may result from an unregulated insurer policy of differential permitted loss ratios. ${ }^{16}$

Per Cent Losses Paid of Premiums Written

\begin{tabular}{|c|c|c|c|}
\hline $\begin{array}{c}\text { All } \\
\text { Classes }\end{array}$ & $\begin{array}{c}\text { Highest Cost } \\
\text { Class }\end{array}$ & $\begin{array}{c}\text { Lowest Cost } \\
\text { Class }\end{array}$ & $\begin{array}{c}\text { Class With } \\
\text { Largest Premium } \\
\text { Volume }\end{array}$ \\
\hline$\cdots 33.2$ & I25.7 & 14.2 & $29 . I$ \\
\hline$\ldots 45.2$ & 84.4 & I3.I & 36.6 \\
\hline$\cdots 35.0$ & 82.7 & 10.3 & 28.9 \\
\hline-39.5 & $30 \pi .5$ & 7.2 & $I 7.0$ \\
\hline
\end{tabular}

Frame protected............33.2

Brick protected...........45.2

Brick and frame protected.....35.0

Fireproof .................. 39.5

For the five years ending with and including 1948 the Pennsylvania state-wide fire loss ratio on the written-paid basis was reported as .3975 . Insurance Commis-

\footnotetext{
12 Id. at 15.

14 Ibid.

${ }^{18}$ Ibid.

${ }^{35}$ Martinesu, op. cit. supra note 8, at $\mathrm{r}_{3}$.

${ }^{10}$ Middie Departasent Association of Fire UNDerhwiters (unpublished manuscript).
} 
sioner Malone, in announcing his approval of revised rates effective October I, 1949, emphasized the point that, although the over-all result of the revision was a 7 per cent average decrease, the rate changes ranged from increases of 25 per cent to decreases of 20. (The permitted loss ratio in Pennsylvania is 45 per cent.) That the Pennsylvania Department believes that the loss ratio technic should be used more effectively toward rate equity is shown by Malone's statement that: ${ }^{17}$

We have reached the place where each class of business should pay its own way and not be carried by other profitable classes. In other words, home owners should not, and will not in the future be compelled to carry the load for the more hazardous risks.

The insurers may reply that class equity is more than a matter of comparative loss ratios, and they are right. It is true, for example, (see page 519) that some classes, residence for example, incur more administrative expense than others, and thus show a smaller profit than the loss ratio data suggest. Since the loss ratio method assumes a uniform relation of insurer administrative expense to loss costs, this amounts to saying that one kind of inequity, incalculable and uncontrolled, tends to cancel another. The loss ratio rate-maker indeed is no better prepared with precise data on expense differences by class than of loss differences. The method does not preclude detailed analysis of insurer adminstrative expense, but it is a fundamental assumption of the method that such analysis is not needed. Until it is forthcoming, however, loss ratio rate-making permits inequities in both loss and expense allocation.

Analysis of the loss ratio method has proceeded to this point without detailed reference to another feature that is often associated with it in a rate structure, the fire rate schedule. As we have seen, the loss ratio method is best suited to, and is primarily used, for assuring adequacy of rate level. This means that a given rating plan, fire schedule for example, may combine the simplicity of the loss ratio principle with methods of risk classification the very reverse of simple. These rate schedules have advantages and limitations of their own and will therefore be considered separately.

The principal criticisms aimed at the fire rate schedules used in the eastern part of the United States are that they are too complex; they are too cumbersome; their application is too expensive; their end-product is not an equitable distribution of loss costs among insured risks. On the first point "... all the experts in our [New York] Department believe that it is possible to work out simpler methods in which the loss experience should be given more weight."18 There may be, there are, important factors inherent in the underwriting situation that explain some of the complexity and cumbersomeness of these fire schedules; what the New York Department is saying is that the factors do not amount to a caveat in perpetuity against analysis and experiment. The same Department in reporting on its examination of the New York Fire Rating Organization concluded on this point that: ${ }^{10}$

\footnotetext{
${ }^{27}$ Statement by James F. Malone, Jr., announcing approval of 1949 rate revision, quoted Weekly Underwriter, September I7, 1949, p. 643, August 6, 1949, p. 29 x.

${ }^{18}$ PrNK, op. cit. supra note 3 , at 1 .

${ }^{10}$ Insurance Department, State of New York, Report on Examination of the New York Fire Rating Organization I2I (I946).
} 
Having got into the elaborate system of schedule rating the fire insurance rating organizations have found it extremely difficult to make changes and adjustments to keep in line with actual experience. The general attitude has been to retain the complicated schedule rating systems with estimates of numerous elements of hazard the costs of which are unknown. The rating organization is opposed to change. . .

A major collateral defect is that they fail grievously in attempting or producing rate equity: $:^{20}$

[Schedule] rate changes that have been made have largely been the result of pressure and agitation from various groups and associations of assureds, agents or companies. Some of the changes were the result of pressure to meet competition of other insurers. Other rate adjustments, long overdue, were not made until requested by the Insurance Department.

Another form of inequity lies in the application of the schedules, in "rating practices arising out of competitive situations...."21 There is no way of measuring this, but the extent of inequity arising through inappropriate use of the schedules is probably as great as that arising from the defects of the schedules themselves.

The obstacles to a more rational and equitable fire schedule considered solely as a method of risk classification are, as we suggested earlier, very real. On risks exposed to many and complex loss-producing factors and developing as low a loss frequency as fire, average rates in the sense of the pure premium method are probably not possible. The fire insurance business is on sound ground when it argues that it has a difficult rate-making job; it is vulnerable though when it accepts its handicaps as permanent and, far from attacking them boldly, erects them into insurance dogma. Time and time again the New York Department has urged the fire insurers to look more carefully into the technics used by their casualty colleagues. To this, and to more specific recommendations for improvement of the schedules, response to date has been slight. The hopeful side of the situation is that not all the obstacles, perhaps not the greatest obstacles, are technical, and traditional barriers, given the will and time, can be broken down or surmounted. We need time to adjust for the fact that: $:^{22}$

For many years the fire insurance companies had operated without state supervision of the rate-making process. ... Many of the rate-regulatory officials . . . did not appreciate the importance of classified experience for rate-making purposes.

Already the New York Department sees "less emphasis on bargaining and more on objective analysis of the experience."23 The Insurance Executives Association, a group of top stock fire officials, is working experimentally on a revised fire rate structure that combines the judgment basis of rating the loss-producing features of the complex individual risk with a uniform expected loss ratio for setting the rate level. It may be years before even this relatively mild reform wins approval by industry and supervisory officials, but the fact of willingness to experiment in making fire

${ }^{20}$ PINK, op. cit. stipra note 3 , at 28 .

${ }^{22}$ lbid.
${ }^{21}$ Martineau, op. cit. stipra note 8 , at I4.

${ }^{23}$ Ibid. 
rates is something new in the fire insurance world. Application of the pure premi. um technic in upstate New York to low-value homogeneous fire classes is another indication of a gradually changing company attitude toward the fire rate problem. An imponderable of incalculable influence that may be counted to work toward more scientific fire rates is the infiltration of the fire companies, particularly as a result of expanding company underwriting powers under the new multiple line laws, by statisticians and actuaries trained in the casualty tradition.

\section{B. Pure Premium}

The central characteristics, and some of the advantages and limitations of the pure premium technic have been suggested, by contrast at least, in preceding pages. A brief analysis of its application by the National Council on Compensation Insurance in making workmen's compensation rates for Virginia will supply a more specific demonstration. ${ }^{24}$

The rate-maker using the pure premium technic sometimes determines his classification relativities first, sometimes the rate level; the choice is one of technical convenience. In the rate revision of our example, that of manual rates effective I949-50, he chose to set the rate level first, that is, to make his best estimate of aggregate compensation costs for all Virginia insured employers for the period of rate application-one year beginning July I, 1949. No single step in any rate-making formula illustrates so clearly not only the use of large amounts of judgment but the need for and the possibilities of statistical-actuarial technics as controls on such judgment. In setting the rate level, the compensation actuary has problems peculiar not only to insurance, fire as well as casualty, for which the price must be set well in advance of the date of sale and delivery of the product, but to the liability lines where insurer liability is not only deferred but indefinite. He must, to begin with, determine rate level between 6 to 9 months before the first day on which the rates will be applied and as much as $2 \mathrm{x}$ months before the last policy runs out at the rate level chosen. This would still be a comparatively simple matter, but in the spring of 1949 , when the new rate structure was created, he had also to reckon with the fact that the latest years for which he had available even fairly mature experience were policy years I945-1946. (Policy year experience is that for all policies written in the calendar year of the same number, that is, the last policy in policy year 1946 will run out December 3r, 1947.) To use even this experience is of course not practicable without testing it statistically in every way possible. These tests, for example, are required to determine the relation between initial reports of and fully developed loss figures for the purpose of adjusting the former (this results from the deferred nature of the compensation insurance obligation), and to determine trends (both in the experience period and for the year of rate application) in order to

\footnotetext{
24 National Council on Compensation Insurance, Memorandum re Rate-Making Procedure as Applied to the Determination of Virginia Manual Rates, April 6, 1949, and related memoranda and other materials.
} 
apply correction factors to pure premiums to bring them up or down to the new cost level. In this revision the rate level selected was one approximately 7 per cent below that of the rates in force for the year ending June 30 , r949.

But the rate structure must not only be adequate, it must also fairly represent differences in insurance cost among employers. The most important basis of employer grouping in workmen's compensation is the classification, which may represent all employers whose workers are exposed to the same industrial process, like blast furnace operators; or (a cruder average) in the same industry or business, as watch manufacturing; or employing workers in the same occupation, for example, clerical employees and chauffeurs. The Virginia I949 filing comprised 475 classifications.

For each of these classifications the actuary computed a pure premium from adjusted I945-I946 policy year losses and payroll data-dollars of compensation losses per \$roo of payroll. Consistent with the standards the compensation actuary sets himself, loss figures were put on the incurred, vis-à-vis the paid, basis, a refinement absolutely essential not only for rate equity but for rate adequacy, since the typical compensation claim is paid in installments, often months and years after the claim is incurred, and to keep his accounts on the cash income-disbursement basis would be to invite bankruptcy. By the same token, premiums were put on the earned, not the written, basis. Ideally each classification would have a payroll exposure large enough to produce results Ioo per cent credible or actuarially reliable. Within a single state, however, few classifications can be expected to show perfect credibility. The pure premiums of the majority cannot be taken at face value. The rate-maker has in this situation two alternatives. The older, and now practically passé, is to combine multi-state experience for the same classification, on the assumption that the advantages of broadened payroll exposure will more than counter-balance the admitted disadvantages that follow when (however competently executed) adjustments are made to take account of loss-causing factors affecting the same industrial classification differently in different states.

The other and more recent approach to this problem, taken over from automobile insurance rate-making, is to apply to the pure premiums developed for each Virginia classification a table of experience credibility. To the extent that the classification on the most recent evidence falls short of full credibility, the actuary applies his controls as it were in depth and not, as in the other approach, in breadth. For example, any Virginia classification showing aggregate expected serious (death and permanent disability) losses equal to $5^{\circ}$ times the average serious award in the state is regarded as perfectly autonomous. As aggregate expected losses for the experience period fall below this standard the pure premium indicated for the individual classification for this period is weighted less and less, with compensating increases in the weight attached to the pure premium now being charged this same classification. That is, instead of matching the experience of non-autonomous classifications in Virginia with that for the same classification outside the state, this 
method matches Virginia loss costs indicated on the latest data with Virginia currently charged loss costs. The assumption underlying this decision-a judgment factor-is that it is sounder to avoid the inequity inherent in the combination of multi-state experience than the instability and inadequacy that may result from insufficient local exposure. ${ }^{25}$

The following exhibit will illustrate application of the National Council credibility formula to Classification 2014 (Milling of Grain). Because they represent quite different loss-producing factors and over time may develop different trends, the compensation pure premium was computed in 3 parts: for serious, non-serious, and medical losses:

Pure Premum Data, Virginia Classification 2014

\begin{tabular}{|c|c|c|c|c|}
\hline & Serious & Non-Serious & Medical & Total \\
\hline $\begin{array}{l}\text { r945-r946 } \ldots \ldots \ldots \ldots \ldots \\
\text { Underlying current rate, }\end{array}$ & $\ldots .02$ & .29 & .27 & .58 \\
\hline at new rate level.... & $\ldots \times 7$ & $.3 \mathrm{I}$ & .28 & .76 \\
\hline Formula $\ldots \ldots \ldots \ldots \ldots$ & $\ldots$... & .30 & .28 & .75 \\
\hline Selected & $\ldots x_{7}$ & .30 & .28 & .75 \\
\hline
\end{tabular}

The effect of the credibility formula, $E^{2}=W^{3}$, in which $E$ equals the volume of expected losses in a classification (expressed as a per cent of volume of expected losses required for full credibility), and $W$ equals a given per cent of credibility, 40, for example, is to give proportionately less credibility and less weight to the most recent experience of the classification as the total of its expected losses drops below the standard for full credibility. In this example serious losses showed no credibility at all, so the most recent indication (which was very far out of line with the underlying pure premuim) was ignored, and the formula pure premium was the result of weighting the underlying premium roo per cent and the 1945 -I 946 premium zero. Non-serious losses with a pure premium of .29 showed 40 per cent credibility which combined with a 60 perr cent weight for the underlying premium of 3 I produced a formula premium of 30 . The credibility of current medical premium was 50 per cent, hence a formula pure premium of 28 .

In the interest of rate stability the actuary selected in each case the middle figure in each pure premium series. Thus, another example of the judgment factor, but as is typical in the use of judgment in the pure premium technic, the judgment enters into selection of statistical-actuarial materials and plan, not in making the rate itself.

Since, unlike the case for those made by the loss ratio method, these rates cover loss costs only, the actuary next added an allowance for profit (Virginia permits $2 \frac{1}{2}$ per cent of final premium) and for expense ( $40 \frac{1}{2}$ per cent of the same base), and a catastrophe loading (a flat charge of one cent per hundred dollars of payroll charged every classification alike). The result is the manual rate.

\footnotetext{
${ }^{25}$ Compare the rationale applied by the New York Insurance Department in testing the credibility of fire experience. "Where the credibility for 5 years is inadequate we resort to ro and even 15 year figures and to out-of-state figures. As a last resort we sometimes combine classes [within the state] to get a broader statistical base." Martinenu, op. cit. supra note 8 , at 16 .
} 
Even this highly skeletonized example of the pure premium method makes it clear that while the principle of the loss ratio method is simple and even crude, that of the pure premium is complex and relatively precise. But where in application the loss ratio technic may be complex indeed, as in the fire rate schedules, that of pure premium is extremely simple. The latter in fact is sometimes under attack because, as in automobile liability manual rates, the rate reflects only a few lossproducing factors-the most important being territory-and ignores others, for example, the record of the individual driver, that to the laymen would seem to have a major bearing on loss costs. To criticism of this kind the actuary has several answers. The strongest perhaps is that in making rates he is bound to emphasize the averages because the great majority-in number-of the risks for which he is making rates present little or no individual risk credibility, and the fewer sub-factors he introduces into the rate structure the more dependable and equitable his pure premiums. $\mathrm{He}$ is on ground all the solider in this position because the superiority of his rate materials and the objectivity of his technic permit him to analyze and collate his pure premium data in any number of combinations, and he can give specific objective answers to hundreds of questions which under the loss ratio technic must remain forever unanswered. The point is here not that the actuary is always right-in the last analysis this must be a matter of judgment-but that the pure premium approach permits him to introduce any desired degree of precision and complexity and that he can show the critics his work at every stage of his computations. In incorporating the expense allowance in the final rate, for example, he need not, as under the loss ratio method, apply the allowance as a flat per cent of final premium, but may and does introduce such variations as expense constants and expense loadings scaled inversely by size of premium.

A collateral answer to the critics on this point is that when the individual risk can qualify for individual rating, it is sounder and more equitable to take account of significant inter-risk differences in this way. The fact is that for the great majority of risks their similarities with other risks are far more important than their differences.

Because the actuary periodically, in compensation and automobile liability annually, recomputes pure premiums, he is again in a strong position when he has to justify his rates to the Commissioner and the buying public.

The objections to the pure premium technic are essentially the same as those urged against classified experience, and, like those, come chiefly from the fire insurers. The "statistical approach" is wrong because it does not produce sound, meaning adequate, rates. There is a strong inference too that "statistical rates" are made by application of exclusively mechanical formulae: ${ }^{26}$

Past experience is of great value but has definite limitations. Sound rates cannot be made on the basis of experience alone. Judgment, other statistics [sic] and all other relevant factors are of equal or of greater importance.

${ }^{20}$ Vestal Lemmon, quoted Weekly Underwriter, May 28, I949, p. 357. 
It is implied also that the pure premium rate-maker indulges in unnecessary and wasteful elaboration: ". . . in the end it will lead to unreasonable burdens on the companies"; and that by forcing uniform rates and covers it will stifle competition. ${ }^{27}$ On the last two charges it is relevant to cite casualty experience. Casualty liability forms are highly standard, but the record is clear that standard forms, however induced (the compensation policy by statute, the automobile by voluntary insurer agreement), in that field have not produced either a decline in competition or less service to the insured, and the burdens on the insurers have not been unreasonable either.

The first of these charges is the most serious. It highlights clearly the fact that refusal to admit the virtues of "statistical rates" is due essentially to the belief that the statistical-actuarial materials are defective as indicators of loss costs, and thus that the major ingredient in the rate must be judgment. To a remarkable extent indeed, the difference between the loss ratio and pure premium technics is one of the relative importance of the judgment factor. The loss ratio method, it is fair to say, and whatever the justification, makes judgment the main test of a proper rate. Judgment is the principal criterion for classifying risks, for fixing schedule debits and credits, for selecting expected loss ratios, and for setting the general rate level. In pure premium rate-making the function of judgment is essentially to assist the actuary to select the statistical-actuarial materials and the technical processes he will apply to them, not to select the rate result. Judgment, that is, is important primarily in setting up the rate-making plan, but once it is adopted the actuary gives the plan, as it were, its head. Ex-Superintendent Dineen has put the contrast between the two technics in this way: $:^{28}$

In the casualty business there is general agreement on the elements and factors entering into a rate revision. Some elements of judgment are necessarily a part of the revision, but many of the steps are largely mechanical. The reverse has been true in the fire business. Great stress-and sometimes too much-has been laid on the element of judgment, not only as to the rate structure itself but as to its components.

\section{IV}

\section{State Rate Regulation: Standards, Issues, Unsolved Problems}

As other papers in this symposium will show, the function of the state in the United States is, generally speaking, not to make rates but to see that they are made in accord with statutory standards of equity, adequacy, and related criteria. (Exceptions are Louisiana, where casualty but not fire rates are made by the state; ${ }^{20}$ Texas, automobile and workmen's compensation rates; ${ }^{30}$ and Massachusetts, compulsory automobile liability rates. ${ }^{31}$ ) That the intent of the typical state law is not only to stop far short of rate-making, but, by stating rate standards in extremely broad terms,

${ }^{27}$ Russeil H. Matthias, Casualty Rate Regulatory Laws and administration (i950).

${ }^{28}$ DINEEN, op. cit. supra note $\mathrm{II}$, at 20-2I.

${ }^{29}$ LA. Gen. Stat. \$\$4030.06, 4030.05 (Supp. 1949).

${ }^{30}$ Texas StAt. tit. 78, arts. $4682 \mathrm{~b}, 4907$ (Supp. 1949).

31 ANn. Laws Mass., c. I75, \$I13B (1948). 
to make plentiful allowance for every variety of insurer and insurance situation, is evident from the statement that accompanied the All Industry-Insurance Commissioners Casualty and Surety Rate Regulatory Rate Bill, now generally the law throughout the country:32.

\section{Principles of State Regulation of Casualty and Surety Rates}

Casualty insurance is constantly changing. It is impossible to anticipate changes which may become desirable. For this reason it is preferable to establish principles of regulation within which administrative authority can exercise a broad discretionary power, rather than to set forth details which, under changed conditions, might stand in the way of desirable developments in rate-making.

The section of the standard rate regulatory law (hereafter referred to as rate law) on the Making of Rates provides inter alia that: ${ }^{33}$

Due consideration shall be given to past and prospective loss experience within and outside this state, to catastrophe hazard if any, to a reasonable margin for profit and contingencies, to dividends, savings or unabsorbed premium deposits ... to past and prospective expenses both countrywide and those specifically applicable to this state, and to all other relevant factors within and outside this state.

Rates shall not be excessive, inadequate or unfairly discriminatory.

The Illinois statute for example copies this language verbatim except that, following the recommendation of the All-Industry Committee (but not of the Insurance Commissioners), it inserts the word underwriting before profit. ${ }^{34}$ The California statute, which covers fire and casualty rates in the same law, also follows the recommended language but expands the omnibus provision at the end to include "all other factors, including judgment factors, deemed relevant within and outside this state," and provides that "in the case of fire insurance rates, consideration may be given to the experience of the fire insurance business during the most recent 5 -year period for which such experience is available."35

The broad terms of the rate laws leave, it is clear, a large margin of responsibility to insurers and state regulatory officials. Technically this responsibility for the insurer is not new; it has rather been spelled out in a law. It is important, in view of the attack by the conservatives on the new rate laws, to keep in mind that for the most part the laws do nothing more than put into statutory form the requirement of compliance with standards that every rate-maker should observe without compulsion. The rate laws do not create the need for sound and equitable rates. They compel more careful scrutiny by the state of the rate-maker's methods. This does not of course amount to saying that the new laws will require no change in insurer, or supervisory, attitudes and policies. If this were so the laws would be useless. The

\footnotetext{
as All-Industry Committec, Casualty and Surety Rate Regulatory Bill, Explanatory Memorandum, Oetober 23, 1946.

${ }^{38}$ National Association of Insurance Commissioners, Casualty and Surety Rate Regulatory Bill $\$ 3$ (1946).

${ }^{34}$ ILl. Stat. AnN. tit. 66.I 28 (3), $\$ 456(\mathrm{I})$ (Supp. I947). (Italics supplied.)

${ }^{35}$ Cal. Ins. Code $§ 1852$ (b) (Supp. 1949).
} 
significance of the imposition of legal sanctions by the rate laws is moreover increased immeasurably because for the first time in this country rate results will no longer be judged solely on the record in a few states. They will be judged not only in each state (in casualty insurance with the exception so far of Idaho) but on the way the states are able to coordinate their individual laws into an acceptable national plan.

In evaluating the new rate laws, four issues assume major importance. In broad terms they may be stated as the issues of $(\mathrm{I})$ the rights and abligations of the independent insurer vis-à-vis rate bureau members; (2) the conforming vis-à-vis the deviating member of the rate bureau; (3) the propriety and amount of an allowance in the rate structure for underwriting profit; and (4) the proper relation between insurance rate and size of risk. The first three are related most frequently to the setting of the general level of rates and in turn of what we have called group or classification rates; the last, to determination of the rate for the individual risk. All have to do generally with both the loss and expense elements in the rate, but the second and fourth are particularly concerned with expense. Under the rate laws the expense element in the rate must meet the same standards as the loss content.

All these issues require in one way or another examination of the difficult and delicate distinction between rate standards and rate uniformity. It is natural in the circumstances, but it does not make for sound conclusions, that the distinction has too frequently not been made. Indeed, as we have seen, it has been alleged that rate standards soon or late will result in uniform rates, uniform policy forms, and even the end of competition. This reasoning ignores the fact that rate standards are not the same as uniform rates, that the new laws pertain to standards for rates, and that there are many kinds and degrees of rate standards.

It is a fair generalization that the purpose, and the effect, of the rate laws is not to achieve uniform rates but, as a condition precedent to application of equity and adequacy standards, to assure collection and interpretation of rate materials on a uniform basis for all insurers whether they choose to join a rate bureau or not. The point is not of basic importance, but it is of some interest to note that there are segments of the insurance industry itself that by no means accept the inference of rate law critics that even uniform rates would be either unsound or illegal. The mutual casualty companies for example take the position that: ${ }^{30}$

There is nothing inherently wrong in price uniformity itself [citing United States Supreme Court decisions on the Sherman Act in other fields]. The casualty insurance business is fundamentally one in which standardization is the rule rather than the exception. . . A substantial degree of uniformity, at least to the loss portion of the rate, is in the public interest in the casualty insurance business.

The position of the mutuals, as the last sentence suggests, is not unrelated to their competitive advantage, but it is a sound one. Uniform rates, it should be noted, in this connection refer to initial rates, that is, rates before policyholder dividends if

\footnotetext{
${ }^{30}$ Special Commtttee on Legislation, american Mutual aliance, Memorandum on State Reguiatton of Casualty Insurance Rates 4 r-44 (November i947).
} 
any. State rate laws in fact, as we shall see presently, permit variation by the individual insurer from uniform rates both in advance of the period of coverage and at the end.

It would be naive of course to suggest that imposition of standards on so vital a part of the insurance transaction will have no repercussions on other parts of the insurance transaction, and these repercussions, immediate and potential, must be kept in mind if the rate laws are to achieve their purpose. The complexity and pervasiveness of the rate process are admitted; the underlying assumption of these laws is that it is better to regulate, as it were, from the center of the insurance transaction outward rather than from the circumference toward the center. It is a sound one.

\section{A. Independent-Bureau Member}

The independent insurer-he who chooses not to join with others in maintaining joint facilities for collecting rate information and making rates, as well as for other inter-insurer functions-has long been a power, particularly in the casualty business. To the spur of the independent and to the open or implicit threat of the more independent-minded bureau members to resign when bureau agreements and policies seem restrictive, must be credited most new ideas (good or bad) in casualty insurance. The independent has been far less important in fire insurance. The new rate laws ${ }^{37}$ in a dozen ways, some general, some specific, make it plain that their purpose is not to discourage the independent insurer. Independent insurers, for example, are permitted to make their own rate filings, and no insurer is required to join a rate organization..$^{38}$ At the same time, a rate bureau must permit any insurer the right to subscribe to its rate-making services, and members and subscribers may adopt individual systems of expense allocation. This last in particular is an extremely potent safeguard of the independent position, since cost competition in fire and casualty insurance centers on differences in insurer expense of operation rather than on loss costs.

The reactions of the independents to the new laws must be judged against the background of the important fact that in the majority of states these laws represent their first experience with rate regulation. Some independents are not assured that the laws protect their managerial rights and responsibilities adequately. "Government, acting through the medium of state insurance commissioners, has no right to dictate the detailed price structure of insurance companies."39 In principle there is likely to be no disagreement on this statement, but in interpreting it everything depends on the content one gives the key words, dictate and detailed. The same question of the meaning of words arises in the demand of the same author that

${ }^{37}$ In the following discussion specific citations to the All-Industry-Insurance Commissioners Bill and related documents and to state laws are omitted. The interested reader may refer to the sources cited notes 29-35 supra.

${ }^{38}$ Workmen's Compensation is sometimes an exception, as in Pennsylvania, where every insurer, including the State Workmen's Compensation Insurance Fund, must join the rate bureau. All the bureau members still retain the privilege of asking for deviation.

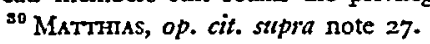


"... a commissioner shall not attempt to substitute his judgment for that of management nor attempt to require management to prove to the nth degree by statistics that the price is correct." The conclusion that "it is sufficient if the price is not excessive, inadequate or unfairly discriminatory" is hardly helpful since it is precisely the function of the commissioner to determine whether a given rate or rate structure meets these standards, and it cannot be assumed that the independent insurer will, unregulated, apply them any more than the unregulated insurer rate bureau. One test of a proper rate suggested by the independents is that of "a mutually acceptable price" to insurer and insured. But this, untempered by general standards, might be only another name for rate-making for purely competitive ends. It is that kind of rate-making that inter alia the new laws are intended to make impossible.

It would seem that the requirement that the independent meet the same rate standards as those imposed on rate bureaus will add handicaps to non-bureau companies, particularly small ones. But if size gives operating advantages in insurance it is not the purpose of the rate laws to redress the balance in favor of the smaller insurers. To make this an objective of the rate laws would be to create a new inequity and a new restriction on competition. Existing independents by no means are all small, but in the future it will undoubtedly be more difficult for new companies to start in the insurance business without joining rate bureaus.

\section{B. Conforming-Deviating Bureau Member}

Even for insurers joining a rate bureau the rate laws permit opportunity for deviation from uniform rates. A deviation is a uniform percentage decrease or increase on the rate filed on all or a class of insured risks. In fact all deviations are minus; plus deviations exist only in the statute because practically when an insurer cannot do business at bureau rates it goes out of business. A deviation is to be distinguished both from a filing by an independent and from changes in and supplements to a filing by a rate bureau.

The grounds for approving deviation, under state regulation of course, are the same as those for permitting insurers to make rates independently: it encourages price competition and thus works in the direction of greater rate equity. The rate laws, following the New York precedent, permit approval of deviation for credible differences between the applicant insurer and the rest of the bureau members either in pure premium or expenses. But, again following New York, they contemplate that most deviations will be permitted for the latter and not the former, because variations of individual insurer loss costs from the average are very much less credible than variations in expense; over the latter the insurer has an important degree of control, over the former relatively little. When the pure premium element in the rate is based on the combined experience of bureau members, an insurer will ordinarily find it difficult to show an appreciable difference between its loss costs and average loss costs entering into the bureau rate. In New York, "each company is presumed to have its share of good and bad risks," ${ }^{, 40}$ which would suggest that

\footnotetext{
${ }^{10}$ State of New York, Instuance Department, Decision in the Matter of Application by the General Accident, Fire and Life Assurance Corporation Ltd. for Continuation of Its Uniform Deviation 2 (1939).
} 
insurers showing better than average loss ratios would be permitted minus deviations, but it has been Department policy to approve deviations only when " . . . the established level of the rating organization does not sufficiently reflect the combined loss experience of all authorized companies." 41 Deviations for loss variations, that is, are restricted to those cases where the bureau rate is excessive, not in comparison with individual insurer experience but with the loss experience of all companies combined. If rates are properly made, there will never be justification for a deviation for this reason, which in the future will be far less likely to occur than in the past. The position of the New York Department, with full knowledge of the consistent ability of individual insurers to do a better job of underwriting than the average, is not entirely logical, but it is a fault on the side of conservatism. The decision is no doubt influenced by the fact that the mutuals, the carriers more likely to produce credible loss variations, have at their command other ways to correct for excessive rates.

\section{Underwriting Profit Allowance}

A usual provision of the rate laws is that consideration shall be given to "a reasonable margin for profit and contingencies," sometimes with the word underwriting inserted before profit. The provision does not of course furnish a guarantee that individual insurers or all insurers combined will be able to show a profit; its purpose, as its combination with a contingency rate allowance suggests, is to provide a safety factor. The argument for such a loading by one insurer official that since "... the more hazardous risks have in the past been under-rated ... it would appear reasonable to load an additional profit margin on the more stable risks, such as dwellings," $" 42$ is one scarcely to be expected in these latter days. This is to purchase over-all rate adequacy at the price of overcharges on selected risk classes, a practice which it is the announced objective of the rate laws to prevent.

The underwriting profit issue is of pressing importance in fire, not in casualty insurance. An allowance in the casualty rate for underwriting profit $-2 \frac{1}{2}$ per cent in casualty excluding compensation-has been allowed for years by the New York Department. Following a recommendation of the National Council on Compensation Insurance, a factor of $2 \frac{1}{2}$ per cent is now included in every state in which the Council either makes or advises on rates; ${ }^{43}$ in the 1949 New York workmen's compensation rate revision the factor approved was $1 \frac{1}{2}$ per cent. In approving a profit factor the NAIC committee recommended that investment earnings be considered as an offset, but compensation and other casualty rates in fact have been made without taking these into account, at least in any direct way. But allowed or not, and on whatever terms, the question has never been the burning issue it is in fire insurance.

\footnotetext{
${ }^{2}$ State of New York, Insurance Department, Memorandum Opinion in the Matter of Demations from RAtes of the National Automobile Underwrtters Associatton 5 (I94I).

${ }^{2}$ D. J. Cowie, quoted Weekly Underwriter, Sept. 3, r949, p. 538.

48 National Council on Compensation Insurance, Annual Report 7 (1949).
} 
The reasons are two: the impact of the new fire rate laws that for the first time made it necessary for insurer or bureau to justify rates by twentieth century standards, ${ }^{44}$ and the belief of the business that sound rates require a margin of safety wider than for most other insurances and that unless this margin is provided the safety of the fire insurance contract will be impaired.

While the main points of dispute over the profit allowance in the fire rate appear to be over the level to be permitted and the elements to be taken into account in computing this allowance, on examination the two prove to be essentially the same. The first question can be settled only after the parties have agreed on answers to the second; once there is agreement on the elements, agreement on level is not likely to be long delayed.

Fire insurers and Commissioners have still to agree on these important matters related to the elements in the profit allowance: should the investment income of the insurer be charged as an offset to the profit allowance; if so, what is the appropriate index of such income; to what extent should computation of the insurer's profit be influenced by adjustment for the effect of the failure of insurer records to make allowance for prepaid expense? ? $^{45}$

On the first of these the fire insurance business takes the position, ${ }^{46}$ reiterating the guarantees it was granted by the Commissioners' r92I formula, that the investment and underwriting operations of fire insurance are completely separate and that the first cannot be considered in making rates. The industry is particularly critical of the recommendation in the McCullough Report in favor of determining the amount of investment income to be set off against the profit allowance as the excess of total investment income (including that from reserves) of fire insurers over what they would earn-assuming the same yield as in their investment portfolios-on their equity capital alone. Earnings of fire insurers over that of other investors with similar investment portfolios but not combining underwriting with investment McCullough considered to be an approximation of the amount of investment income resulting from the underwriting process, and thus to belong to the insured and not the insurer. The doctrine or the dogma of the inviolacy of fire insurance investment

* While the pioneer Kansas rate law applied to fire insurance and included standards of rcasonableness, adequacy and non-discrimination, most fire rate laws included only the last of these standards and did not include the all-important requirement that rates be filed and approved by a supervisory official. In these last requirements is the distinctive and vital feature of the modern rate regulatory law.

${ }^{4}$ Materials on which the following discussion is based are: Special, Subcommittee of the Fire. and Marine Committee, National Association of Insurance Commissioner; Second Report reUnderwrting Profit or Loss Etc. (McCullough Report) (October 9, i947); Special Subcommittre on Underwriting Profit or Loss, Fire and Marine Committee, NaIC, Statement (June 9, 1948); Committee on Latws, National Bosrd of Fire Underwriters, Report (June 3, 1949); and related official documents.

${ }^{48}$ Compare the situation in workmen's compensation insurance where since December 1948 it has been agreed that a profit factor be incorporated in the rate formula, "but that the factor used should be demonstrated for each state by factual data to be such that it' will produce only a just and reasonable return on invested capital and surplus devoted to workmen's compensation business, with due consideration being given to any special conditions of individual states and to investment earnings." Rocber, Best's Insurance News, Fire and Casualty Edition, April 1949, p. 29, quoting the report of the Workmen's Compensation Committee of the NAIC, December 1948 . 
income is extended here to the transparent argument of the companies that reserves are taken from surplus and therefore are the property of the stockholders.

The industry likewise disagrees with the McCullough recommendation that underwriting expense figures be adjusted to reflect the difference between paid and incurred expense. In general it rests its case on its legal position under the Commissioners' standard profit formula of Ig2I, which approved a 5 per cent profit (and a 3 per cent conflagration) allowance, but against which the companies in New York have actually earned for the 25-year period ending 1945 a statutory underwriting profit of only .oI7 per cent. ${ }^{47}$ McCullough, observing that in New York "the fire insurance business has been able to prosper through the 25 years on a statutory underwriting profit of less than 2 per cent" concluded that the I92I formula was excessive. The industry countered by pointing out that between 1939 and 1949 policyholders' surplus of fire companies in the United States declined from 150 to 70 per cent. ${ }^{48}$

In conclusion McCullough suggested that a return of 6 per cent, computed by comparing combined underwriting and investment income, adjusted for prepaid expenses, with equity capital invested in the insurance business, should be considered adequate.

The issues are not yet resolved. So tangled are the questions of law and so meager the pertinent facts that in its 1949 Report the Special Subcommittee of NAIC, of which Superintendent Dineen was chairman, chose to recommend continuance of the status quo and further study. The following quotations are from this Report:

On the issue of investment income:

The subcommittee is . . agreed that it would be impracticable at this time to attempt to incorporate a direct recognition of investment income attributable to underwriting in the mechanics of the fire insurance rating process.

While the subcommittee accepted the insurer contention and the rule of law that reserve funds are owned by the insurer, it, not too logically, recommended study of a series of questions that suggest that part at least of investment income may in fact derive from the underwriting function. The qualifier, underwriting, had been included in the profit provision of some state rate laws with the objective of precluding consideration of investment income in making rates, but the committee concluded that so far no one knows what the effect of this revised language may be.

On the issue of correcting insurer expense data to put them on an incurred basis for rate-making the subcommittee concluded, in a remarkable piece of circular reasoning, that:

Since such an asset account would be inadmissible in an insurance statement, it is the determination of the committee that no such adjustment should be made for annual statement purposes.

${ }^{47}$ MiCCULLOUGH REPORT, op. cit. stpra, note 45, at 52-53, 50. Statutory underwriting profit is without adjustment for the premium reserve equity resulting from failure of the insurer's system of accounts to allow for prepaid expenses.

${ }^{68}$ D. J. CowiE, Weekly Underwriter, October I, 1949, p. 809. 
On the amount of the profit allowance, the committee recommended that the 5 per cent of the r921 formula be continued, plus one per cent for catastrophes, with a proviso that, to encourage stability, rates should not be revised unless they fall outside the 4 to 8 per cent range, or two per cent on either side of the maximum of 6.

\section{Insurance Rate and Size of Risk}

This issue, though under somewhat different guise, is of importance both in fire and casualty insurance. In the former, however, as with so many other regulatory issues, it has come only very recently to Commissioner and public attention, and appears to have generated that much more heat for the delay. In fire insurance the question of the relation of rate to risk size occurs principally in setting the rate for the individual risk large in the sense that it covers multiple locations. (The actuary defines individual risk as the combined exposures, wherever they are, of a single insured.) Large risks in casualty insurance are not only of this variety but also very typically are large exposures in a single location. The incidence of administrative cost will not be the same for these two kinds of large risks.

The factor of risk size may reflect itself in loss costs, in expenses of the insurer, or both. In general and for all lines, inverse correlation between risk size and insurer administrative expense is obviously much more likely than between risk size and pure premium. This is because some insurer expenses, for example, home office and policy-writing, are of the nature of overhead cost, which, as the risk increases in size, work out as decreasing proportions of total premium. Expense reductions due to this cause are much less likely in multiple than in single-location risks. By the same token, administrative costs, however small the risk, will not fall below a certain absolute figure. Since increase of exposures as such, unless related to superior management as in workmen's compensation, will have no necessary relation to the insured's loss record, and since except in workmen's compensation data on this point are lacking, the size factor as far as the loss element in the rate goes is very undeveloped.

The casualty rate-maker, on evidence of varying degrees of credibility, recognizes differences in cost by risk size in different ways: in manual rates by minimum premiums and expense constants; in individual risk rating by premium discount and various kinds of retrospective experience rating plans. The last kind of plan likewise takes into account the loss record of the individual risk, but its most debated feature-one shared with premium discount plans-is its scaling of commission rates downward with increasing total premium. Retrospective Rating Plan D, newest of retrospective plans, also permits combination of compensation and liability risks for individual risk rating, and both premium discount and retrospective plans are applied to multi-state locations. Insurer and Commissioner committees are at work in compensation insurance to develop more and more refined data on the factor of risk size, and a special subcommittee of NAIC recommends that "the pro- 
cedure encompass other lines of insurance as well as workmen's compensation." ${ }^{39}$

Casualty rates also quite generally take into account the factor of risk size in determining the allowance in the rate for losses: in manual rates through the loss constant (it is well established that in the same classification smaller risks tend to have poorer experience); in individual risk rates through prospective and retrospective experience rating. The common feature of the last two plans is their emphasis, much greater in retrospective plans, on the loss costs of the individual risk. Both experience rating plans likewise are generally of multi-state application. Such application would have come even sooner had it not been for the great disparity of state regulatory standards prior to Public Law 15; and indeed it has been argued that unless rate-making technics and state standards are reasonably uniform the loopholes that will result or be deliberately created by this disparity will lead to the early collapse of state regulation.

The fire insurance business, only now beginning to attack the risk size issue in a serious way, has hunches and opinions on the subject but few facts. On the expense side, the New York Fire Rating Organization, for example, reported in 1943 that while average annual residence fire premium in New York is in the neighborhood of $\$ 5$, "the cost of writing a policy and placing it on the books is somewhere between $\$ 2$ and $\$ 4$, excluding commissions and other expense factors." ${ }^{\text {"50 }}$ This is suggestive but data of this sort are hardly suitable to support a rate filing under the new laws; there is even less statistical evidence to light up the current controversy over the proper way to rate multi-state, multi-location risks.

In I927 fire insurers through the Eastern Underwriters Association developed their first plan for rating multi-state contents risks, particularly chain store, and created Interstate Underwriters Board to operate it. The function of IUB was to be advisory only, and the extent of rate-making to be performed by IUB was to "gather from state rating organizations the local rates," from which IUB was to compute "an accurate average rate ... based upon the correct local tariffs as published by the rating bodies in the states where the property is located." "rI IUB, still in an advisory capacity, was to apply to this average rate a percentage reduction or addition to reflect the characteristics of the individual risk not measured in the average rate. "This factor is based on judgment. The elements apparently entering into it are experience of the class, competition, size of account [total premium?], number of locations and experience of the risk." The rating plan, that is, was intended to reflect both loss and expense variations of the risk from the average in a rather unusual combination of group and prospective experience rating. In reporting on its examination of IUB, the New York Department concluded that while it might be feasible to work out a sound procedure for combining these, IBU had made no effort to do so. Such attack would "call for actuarial treatment which has been unheard of in the

\footnotetext{
io National Council on Compensation Insurance, Annual Report 7 (ig48).

${ }^{\Delta 0}$ DineEN, of. cit. supra note $\mathrm{Ir}$, at 9 , quoting brief filed with the New York Department by NYFRO.

${ }^{51}$ State of New York, Insurance Departinent, Report on Examination of the Interstate UNDERWRITERS BOARD ETC. 2, 3, 32, 57 (Oct. 22, 1941).
} 
fire insurance business." Superintendent Dineen concluded that "in actual practice the rate was determined competitively following consultations between the broker, the company and IUB."52 Somewhere also in its history IUB had dropped its advisory function, and "it actually made rates." Small wonder, then, that entirely apart from its other faults as a rate plan, IBU throws so little light on the risk size question.

Current discussion on the relation between fire rate and risk size revolves about the pros and cons of the Escott Plan, approved in 1949 by the New York Department after a brief interlude during which multi-risk rates were made exclusively as an average of specific location rates, with no debits or credits as under IUB. (IUB had been abandoned because NAIC would not approve it as an advisory rate bureau.) The principal feature of the Escott Plan is its provision for adjustment of average specific location rates by the amount that combined loss and loss expense departs from a permitted loss ratio of 55 per cent. ${ }^{63}$ This permitted loss ratio, $7 \frac{1}{2}$ per cent higher than for fire insurance generally in New York, is intended roughly to reflect a presumably lower level of expense for multiple than for single location risks. As a result of the loss ratio approach, by which rates for multi-location risks will continue to be made, the Plan by this feature combines an indeterminate degree of autonomy for individual risk loss experience with a reduced but indeterminate flat expense loading; on this point compare the simplicity of operation and the certainty of results were the pure premium method applied as in casualty prospective experience rating. Despite a complete absence of data to support the Plan, the New York Department approved it, pending further study by the New York Fire Insurance Rating Organization, the New York Department, and NAIC.

The fire insurance business, to say the least, is not unanimously in back of the Escott Plan. The dissenters include some of the largest and most powerful carriers. It is typical of the lack of reliable information on the subject that part of the opposition claims that the Plan discriminates unfairly against the small policyholder because large risk reporting-form business costs as much to handle as small. In this respect much is expected of the results of New York Department Regulation 30, which since January I, 1949 has prescribed standards of uniform expense accounting in fire and casualty insurance.

\section{Conclusion}

The goals of the rate-maker are few and, stated in general language, simple and universally accepted. As for God, country, and motherhood, who could be against them? The effect of even the most elementary study of the rate-making process,

\footnotetext{
52 Robert E. Dineen, State Regulation of National Rates: IUB Afrer SEUA 2, 7 (i949):

${ }^{33}$ State of New York, Insurance Departaent, Letter of Approval re Multiple Locations Risks (September 6, 1949).
} 
however, is to show how difficult it is to translate these goals into specific plans capable of commanding general support. The fault is not of the rate-maker. It is a condition inherent in his job and in the legal, economic, and human circumstances in which he is asked to perform it.

Some of the limits on the effectiveness of the rate-making process, we have seen, lie in the nature of the rate itself. As long, for example, as rates for most risks are made of historical data and for exposures so slight they require combination with other exposures, so long will it be necessary to accept the actuary's results for precisely what they are-broad averages. One corollary of this is that rate adequacy must come before rate equity. Other limits, to be discussed in detail in other papers in this symposium, are inherent in the American tradition of private insurance enterprise combined with public regulation. We have in insurance matters, generally speaking, chosen the middle way: between the extremes of laissez-faire typified by the traditional British position on insurance and of a state monopoly typified by conservative fears of the trend of events in Britain today. This tradition is a compromise, and like all compromise, represents a more or less satisfactory and stable balance of forces; but given the American temperament, likely to be tipped toward the enterprise and not the regulatory side of the formula. Or at least so it has been. Much of the opposition in fire insurance ranks to rate regulation indeed is not against specific laws but against the idea of any regulation at all. The record of American rate regulation is not fairly read except against this background of the American temperament. This social limit on the effectiveness of the rate regulatory process is joined intimately with and strengthened by the constitutional limits inherent in the American system of federated states, and is indeed only another aspect of the ancient American tradition against government controls and, above all, a central government. This indeed is the central dilemma posed by the basic assumption of Public Law I5: that a business, if ever there was one, that must be transacted over state and national lines, can be effectively regulated through a congeries of state jurisdictions constitutionally, and often actually, independent. Insurer officials have predicted, indeed, that unless the multi-state risk problem is properly and fairly promptly solved by the states, federal regulation is inevitable. ${ }^{54}$

In the immediate present, a fourth limit on the effectiveness of the rate-making process is imposed by the inability of the average state to provide personnel and other facilities required for sound results. ${ }^{5 \tilde{J}}$ Luckily in this respect, even if it might prefer to do so, it is not feasible for an insurer to conduct its business, including ratemaking, in one way in New York and in a completely different way in all the other states; these other states, as the reader of this paper will suspect, have been thesometimes unwilling-beneficiaries of New York's leadership. One suspects that

\footnotetext{
*4 Cf. James M. Cahill, Eastern Underwriter, December I7, 1948, p. 83 .

${ }^{t}$ This, in combination with the second limit above, explains the overwhelming preference in state rate laws for the subsequent-approval vis-à-vis the prior-approval variety.
} 
even without the lifting power of the Appleton Rule, New York will continue to lead and instruct her sister states, an accident of insurance history for which the strong states' rights proponent should give the most fervent thanks. This last will in any case in time disappear. In the not-so-long-run, our record of state regulation will be conditioned primarily by the extent to which the insurance business-particularly fire-is able to accustom itself to the new relation between insurer and state, and by the ingenuity and the willingness of the states to work out mutually acceptable and socially sound methods of achieving their common objective. 